\title{
Failed noninvasive positive-pressure ventilation is associated with an increased risk of intubation-related complications
}

Jarrod M Mosier ${ }^{1,2,4^{*}}$, John C Sakles ${ }^{2}$, Sage P Whitmore ${ }^{3}$, Cameron D Hypes ${ }^{1,2}$, Danielle K Hallett ${ }^{2}$, Katharine E Hawbaker ${ }^{2}$, Linda S Snyder ${ }^{1}$ and John W Bloom ${ }^{1}$

\begin{abstract}
Background: Noninvasive positive-pressure ventilation (NIPPV) use has increased in the treatment of patients with respiratory failure. However, despite decreasing the need for intubation in some patients, there are no data regarding the risk of intubation-related complications associated with delayed intubation in adult patients who fail NIPPV. The objective of this study is to evaluate the odds of a composite complication of intubation following failed NIPPV compared to patients intubated primarily in the medical intensive care unit (ICU).

Methods: This is a single-center retrospective cohort study of 235 patients intubated between 1 January 2012 and 30 June 2013 in a medical ICU of a university medical center. A total of 125 patients were intubated after failing NIPPV, 110 patients were intubated without a trial of NIPPV. Intubation-related data were collected prospectively through a continuous quality improvement (CQI) program and retrospectively extracted from the medical record on all patients intubated on the medical ICU. A propensity adjustment for the factors expected to affect the decision to initially use NIPPV was used, and the adjusted multivariate regression analysis was performed to evaluate the odds of a composite complication (desaturation, hypotension, or aspiration) with intubation following failed NIPPV versus primary intubation.

Results: A propensity-adjusted multivariate regression analysis revealed that the odds of a composite complication of intubation in patients who fail NIPPV was 2.20 (Cl 1.14 to 4.25), when corrected for the presence of pneumonia or acute respiratory distress syndrome (ARDS), and adjusted for factors known to increase complications of intubation (total attempts and operator experience). When a composite complication occurred, the unadjusted odds of death in the ICU were 1.79 (95\% Cl 1.03 to 3.12).

Conclusions: After controlling for potential confounders, this propensity-adjusted analysis demonstrates an increased odds of a composite complication with intubation following failed NIPPV. Further, the presence of a composite complication during intubation is associated with an increased odds of death in the ICU.
\end{abstract}

Keywords: Intubation; Critical care; NIPPV; Noninvasive positive pressure; Airway management; Desaturation; Hypotension; Aspiration; Delayed intubation

\footnotetext{
* Correspondence: jmosier@aemrc.arizona.edu

${ }^{1}$ Section of Pulmonary, Critical Care, Allergy and Sleep, Department of

Medicine, University of Arizona, 1501 N Campbell Ave., Tucson, AZ 85721,

USA

${ }^{2}$ Department of Emergency Medicine, University of Arizona, 1609 N. Warren

Ave., Tucson, AZ 85724, USA

Full list of author information is available at the end of the article
} 


\section{Background}

The use of noninvasive positive-pressure ventilation (NIP PV) for acute respiratory failure has increased over the last two decades $[1,2]$ and has shown a benefit in the treatment of acute respiratory failure due to chronic obstructive pulmonary disease (COPD), congestive heart failure (CHF), and in immunocompromised patients [3-12]. Data for the use of NIPPV for other causes of acute respiratory failure such as asthma, pneumonia, or acute respiratory distress syndrome (ARDS) are scant $[13,14]$. Despite the lack of evidence, NIPPV is still often used in these conditions [2], while outcomes data such as mortality, rate of intubation, and other complications following the use of NIPPV for the treatment of respiratory failure are concerning [2,14-23].

While NIPPV use has been shown to decrease the need for intubation in patients with respiratory failure regardless of etiology, there are no data regarding the risk of intubation-related complications associated with delayed intubation in adult patients who fail NIPPV. Several studies have demonstrated an increase in mortality with delayed intubation after failed NIPPV in acute respiratory failure and after failed extubation $[1,15,17,18]$. Given the limited physiologic reserve and high risk of hypoxemia, hemodynamic deterioration, and even cardiac arrest with intubation in critically ill patients [24-30], complications experienced with delayed intubation in these patients may partially explain the mechanism for the increased mortality seen with failed NIPPV requiring intubation. While hemodynamic deterioration, hypoxemia, and aspiration are risks of intubation in all critically ill patients, this study seeks to evaluate if intubation after failed NIPPV increases this risk when compared to patients intubated in the medical intensive care unit (ICU) without a trial of NIPPV. Some of the results of this study have previously been presented in abstract form [31].

\section{Methods \\ Study design}

This is an observational study comparing patients intubated after failed NIPPV versus those patients intubated without undergoing a trial of NIPPV. The failed NIPPV group includes all patients intubated after initially undergoing NIPPV prior to intubation identified in our continuous quality improvement (CQI) database from 1 January 2012 to 30 June 2013. The primary intubation group was selected from the CQI database for comparison. This project was reviewed and approved by the university's institutional review board.

\section{Setting and population}

This study was conducted at a major academic referral center with a 20-plus bed medical ICU, which is staffed by two teaching teams. This ICU service is affiliated with ACGMEaccredited 3-year pulmonary/critical care medicine (Pulm/
CCM) and 2-year critical care medicine (CCM) fellowship programs with a total of 16 fellows. Each teaching team is staffed with an attending (Pulm/CCM or CCM), a fellow (postgraduate year (PGY) 4 to 6), and resident (internal medicine PGY 1 to 3 and emergency medicine PGY 2) physicians. Occasionally, fellows from anesthesiology or surgical critical care fellowships rotate through the medical ICU service. All intubations are performed under attending supervision. For the duration of the study period, direct laryngoscopes were available in all sizes of Macintosh and Miller blades. Video laryngoscopes were available throughout the entire study period and are the preferred device used in the medical ICU. The following video laryngoscopes were available during the study period: GlideScope (GVL) (Verathon, Bothell, WA, USA) with both reusable and disposable blade configurations in sizes 3 and 4, and the C-MAC (Karl Storz, Tuttlingen, Germany) with Macintoshtype blade sizes 3 and 4 . In addition to direct and video laryngoscopes, flexible fiber-optic bronchoscopes are available and occasionally chosen as the initial device for suspected anatomically difficult airways.

\section{Selection of participants}

All patients intubated on the medical ICU service are recorded in a CQI database. Following each intubation, the operator completes a data collection form, which includes information regarding patient and operator demographics, circumstances of the intubation including presence and duration of NIPPV therapy prior to intubation, indication for intubation, devices and pharmacologic agents used for intubation, presence of certain difficult airway characteristics (DACs), pre-oxygenation methods, the number of attempts at intubation, the outcome of each attempt, and complications. All patients intubated after failing NIPPV for acute respiratory failure were included in the study and compared to patients intubated without a trial of NIPPV. Since cardiac arrest patients were not eligible for consideration for NIPPV, they were excluded from this analysis.

\section{Methods of measurement}

The following information was extracted from the patients' medical record: pre- and post-intubation vital signs, preand post-NIPPV and intubation blood gas data, severity of illness (simplified acute physiology score (SAPS II) and acute physiology and chronic health evaluation (APACHE II and IV)) at the time of intubation, and outcomes data including ventilator days and ICU mortality. Patient and operator demographics as well as the circumstances regarding the intubation were obtained from the CQI collection form including operator postgraduate year, method of intubation, difficult airway characteristics (DACs), and device(s) used, as well as the attempts and outcome of each attempt. Methods of intubation included rapid sequence intubation 
(RSI) in which a paralytic agent was used, oral intubation in which a sedative agent only was used (SED), and oral intubation in which no medications were used (OTI).

We utilized a list of DACs that were chosen because they are feasible for the operator to determine prior to intubation in an emergent setting by simple examination of the patient. These include both anatomic and physiologic DACs. The anatomic DACs that make either visualization of the glottic inlet or placement of a tracheal tube difficult included the presence of blood, vomit, or secretions in the airway, cervical immobility (intrinsic or due to a cervical collar), obesity, a large tongue, a short neck, a small mandible, facial or neck trauma, airway edema, and limited mouth opening. Physiologic DACs included hemodynamic instability and hypoxemia, which may make the process of intubation more challenging and are likely to influence the intubation plan.

We defined NIPPV failure as the need for intubation, despite NIPPV support, whether due to refractory hypoxemia, hypoventilation, work of breathing, decline in mental status, failure to tolerate the device, or a change in treatment plan at the provider's discretion. Complications evaluated include hypotension, desaturation, esophageal intubation, aspiration, airway trauma, and 'others.' For this analysis, hypotension, desaturation, and aspiration were considered to be the important complications of interest in that they may plausibly be affected by delayed intubation after a trial of NIPPV. The other monitored complications were felt to be equally likely to occur between the two groups as they are more related to the procedure and independent of the physiology. We defined hypotension as any drop in blood pressure requiring intervention such as fluid resuscitation or initiation or titration of vasopressors that occurred during or within $5 \mathrm{~min}$ of the intubation. Desaturation was defined as a decline in oxygen saturation $>10 \%$ from the baseline during the intubation procedure. Aspiration included any witnessed aspiration of gastric contents during the intubation attempt. For this analysis, these three complications were combined into a composite complication to represent the risk of delayed intubation after a failed NIPPV trial.

The data collection forms were reviewed by the primary author for completion following the procedure. If the forms had any missing data that could not be obtained from the medical record, they were returned to the operator for completion. If information on the form contained inconsistencies, the operator was interviewed by the primary author for clarification.

The data were then entered into the electronic database (Excel for Macintosh 2011 (Microsoft, Redmond, WA, USA)) and transferred to Stata for analysis (Stata version 12; StataCorp, College Station, TX, USA).

\section{Outcome measures}

The primary outcome measured was the incidence of a composite complication (desaturation, hypotension, or aspiration) during intubation. The secondary outcome measured was the odds of death in the ICU following the occurrence of a composite complication during intubation.

\section{Primary data analysis}

Summary statistics were generated for patient, intubation, and operator characteristics using Fisher's exact test for categorical variables, the Kruskal-Wallis test, and Student's Ttest where appropriate. A propensity score for receiving NIPPV for respiratory failure was generated from prespecified variables expected to affect the decision to use NIPPV and included respiratory failure after failed extubation within the last $72 \mathrm{~h}$, blood present in the airway, vomit present in the airway, obesity, hemodynamic instability, hypoxemia, and SAPS II. A propensity-adjusted multivariate logistic regression model was chosen for this analysis because it was thought that certain variables might affect both the clinician's decision to use NIPPV versus invasive mechanical ventilation and simultaneously affect the likelihood of a composite complication, thus, introducing confounding. Propensity adjustment seeks to adjust the model to eliminate this type of confounding on the basis of treatment assignment. The analysis is performed by first generating a propensity score estimating the probability of treatment assignment then performing a logistic regression adjusted for the propensity score. This has the effect of reducing the influence of nonrandomized treatment selection and, assuring that conditional on the propensity score, the distribution of measured baseline covariates will be similar between the two treatment groups [32].

A propensity-adjusted multivariate logistic regression analysis was then performed modeling the odds of a composite complication [32]. The predictor variable of interest was failed NIPPV. Other variables that were likely to confound the occurrence of a composite complication were added to the model in a stepwise fashion and included the presence of pneumonia or ARDS, total attempts at intubation, device used for intubation, reason for intubation, and postgraduate year of the operator performing the intubation. Variables were removed if the odds ratio of the predictor variable did not change by more than 0.1 . A Hosmer-Lemeshow test was performed on the propensityadjusted model for goodness of fit. An unadjusted odds ratio was calculated for the secondary outcome of interest (risk of a death in the ICU) with the occurrence of a composite complication during intubation. Descriptive statistics were performed on measured variables with reported means, standard deviations, medians, and interquartile ranges (IQR) where appropriate.

\section{Results}

Over the 18-month study period, a total of 287 patients were intubated. Five patients were excluded due to cardiac 
arrest, and 47 patients were excluded for incomplete data. Of the remaining patients, 125 patients were intubated after failed NIPPV and constituted the failed NIPPV cohort. Of these 125 patients, 28 patients were given a trial of NIPPV for respiratory failure after extubation within the preceding $72 \mathrm{~h}$. The remaining 110 patients were intubated without a trial of NIPPV and were selected for comparison. Table 1 summarizes the baseline patient and operator demographics. There were no differences in age or gender between groups. There were few differences in difficult airway characteristics between the two groups. Fewer patients intubated after failed NIPPV had blood present in the airway $(7 / 125,5.6 \%$ vs. $25 / 110,22.7 \%$; $p<$ $0.001)$, airway edema $(5 / 125,4.0 \%$ vs. $15 / 110,13.6 \% ; p=$ 0.01 ), or hypoxemia defined as oxygen saturation $<88 \%$
(26/125, 20.8\% vs. 43/110, 39.1\%; $p=0.003)$ compared to patients intubated primarily. However, more patients in the failed NIPPV group had a short neck (47/125, 37.6\% vs. $22 / 110,20.0 \% ; p=0.004)$ compared to patients intubated primarily (Table 1 ).

Patients that failed NIPPV had significantly lower severity of illness scores (APACHE II, APACHE IV, and SAPS II) than the group that was primarily intubated $(p<0.001$, Table 1). The SAPS II score demonstrated the largest difference between the groups with the median score and mean predicted mortality being $38 \%$ and $29.4 \%$ in the failed NIPPV group versus $46.5 \%$ and $41.6 \%$ in the primarily intubated group $(p<0.001)$. Of patients intubated after failed NIPPV, 64\% (80/125) were intubated for hypoxemic respiratory failure compared to $45.5 \%(50 / 110)$ of patients

Table 1 Patient demographics

\begin{tabular}{|c|c|c|c|}
\hline Characteristics & Primary intubation $(n=110)$ & Failed NIPPV $(n=125)$ & $p$ value \\
\hline Mean age, years & 58.1 (IQR 50 to 67) & $61.2($ IQR 54 to 73) & 0.13 \\
\hline \multicolumn{4}{|l|}{ Gender } \\
\hline Male & $57 \%(63)$ & $61 \%(76)$ & 0.60 \\
\hline \multicolumn{4}{|l|}{ DACs } \\
\hline Total DACs (median) & 2 (IQR 1 to 3) & 2 (IQR 1 to 3$)$ & 0.83 \\
\hline None & $21.3 \%(23)$ & $24 \%(30)$ & 0.64 \\
\hline Cervical immobilization & $3.6 \%(4)$ & $4.8 \%(6)$ & 0.75 \\
\hline Blood in airway & $22.7 \%(25)$ & $5.6 \%(7)$ & $<0.001$ \\
\hline Vomit in airway & $4.6 \%(5)$ & $4.8 \%(6)$ & 1.00 \\
\hline Facial/neck trauma & $0.9 \%(1)$ & $0.8 \%(1)$ & 1.00 \\
\hline Obesity & $27.3 \%(30)$ & $37.6 \%(47)$ & 0.10 \\
\hline Short neck & $20.0 \%(22)$ & $37.6 \%(47)$ & 0.004 \\
\hline Large tongue & $13.6 \%(15)$ & $20.0 \%(25)$ & 0.23 \\
\hline Airway edema & $13.6 \%(15)$ & $4.0 \%(5)$ & 0.01 \\
\hline Small mandible & $13.6 \%(15)$ & $18.4 \%(23)$ & 0.38 \\
\hline Hypoxemia & $39.1 \%(43)$ & $20.8 \%(26)$ & 0.003 \\
\hline Hemodynamic instability & $24.6 \%(27)$ & $20 \%(25)$ & 0.43 \\
\hline Limited mouth opening & $8.2 \%(9)$ & $12 \%(15)$ & 0.39 \\
\hline Secretions & $9.1 \%(10)$ & $12.8 \%(16)$ & 0.41 \\
\hline \multicolumn{4}{|l|}{ Illness severity } \\
\hline \multicolumn{4}{|l|}{ Mean (median, IQR) } \\
\hline APACHE ॥ & $19.4(18, I Q R 14$ to 24$)$ & $15.2(14$, IQR 11 to 18$)$ & $<0.001$ \\
\hline Mortality mean/median & $35.9 \%(29.1 \%)$ & $24.3 \%(19 \%)$ & $<0.001$ \\
\hline SAPS $\|$ & $46.9(46.5$, IQR 37 to 57$)$ & 40.1 (38, IQR 31 to 49) & \\
\hline Mortality mean/median & $41.6 \%(38 \%)$ & $29.4 \%(21 \%)$ & $<0.001$ \\
\hline APACHE IV & $85(85.5$, IQR 64 to 102$)$ & $73(69$, IQR 57 to 90) & \\
\hline Mortality mean/median & $37.4 \%(36.5 \%)$ & $24.6 \%(20 \%)$ & \\
\hline Hypoxemic respiratory failure & $45.5 \%(50)$ & $64 \%(80)$ & 0.006 \\
\hline Pneumonia or ARDS & $31 \%(34)$ & $49 \%(61)$ & 0.008 \\
\hline
\end{tabular}

NIPPV, noninvasive positive-pressure ventilation; IQR, interquartile range; DACs, difficult airway characteristics; SAPS, simplified acute physiology score; APACHE, acute physiology and chronic health evaluation; ARDS, acute respiratory distress syndrome. 
intubated primarily, $p=0.006$. Nearly half of patients intubated after failed NIPPV (49\% (61/125)) were intubated for either pneumonia or ARDS, whereas only 31\% (34/ 110) of patients intubated primarily had pneumonia or ARDS, $p=0.008$ (Table 1).

For the patients treated with NIPPV, the location of NIPPV initiation was the emergency department in $11.6 \%$, the ICU in $77.7 \%$, and the general medical ward in $10.7 \%$. The most common reason for initiation of NIPPV was hypoxemia (55.9\%), followed by hypercapnea (25.4\%), and increased work of breathing (8.5\%) (Table 2). The reason for intubation as selected on the data form was different between the two groups $(p<0.001)$. Most notably, $91.2 \%$ of the failed NIPPV group were intubated for respiratory failure versus $62.7 \%$ of the primarily intubated group. The primary intubation group was intubated more often than the failed NIPPV group for airway protection, hemodynamic instability, and severe acidosis $(26.4 \%$ vs. $6.4 \%, 5.5 \%$ vs.
$0.8 \%$, and $3.6 \%$ vs. $0.8 \%$, respectively) (Table 2 ). There were no significant differences in the method of intubation, number of intubation attempts, or the PGY level of the operator between the two groups (Table 2).

The first attempt success rate for primary intubation patients was slightly higher, but not statistically different (77.3\% vs. 69.6\%, $p=0.24$ ) (Table 3 ). There were no significant differences in the mean number of ventilator days (primary intubation 7.85 IQR 3 to 9, failed NIPPV 9.0 IQR 3 to 10 ), number of ICU days (primary intubation 11.5 IQR 5 to 15 , failed NIPPV 15.1 IQR 5 to 16 ), or mortality rate (primary intubation $35.5 \%, 95 \%$ CI 26.3 to 44.5 ; failed NIPPV 29.5\%, 95\% CI 21.5 to 37.7) (Table 3).

Table 3 demonstrates the complication rates between the two groups. There were no statistically significant differences in rates of hypotension (primary intubation 27.3\%, 95\% CI 19.2 to 36.6; failed NIPPV 32\%, 95\% CI 23.9 to 40.9 ) and desaturation (primary intubation $23.6 \%$,

Table 2 NIPPV and intubation demographics

\begin{tabular}{|c|c|c|c|}
\hline Characteristics & Primary intubation $(n=110)$ & Failed NIPPV $(n=125)$ & $p$ value \\
\hline \multicolumn{4}{|l|}{ Reason for NIPPV } \\
\hline Hypoxemia & - & $55.9 \%(66)$ & - \\
\hline Hypercapnea & - & $25.4 \%(30)$ & - \\
\hline Work of breathing & - & $8.5 \%(10)$ & - \\
\hline Other & - & $10.2 \%(12)$ & - \\
\hline Duration of NIPPV & - & & - \\
\hline Mean/median (h) & - & $12.3 / 5.8$ & - \\
\hline Reason for intubation ${ }^{a}$ & & & $<0.001$ \\
\hline Airway protection & $26.4 \%(29)$ & $6.4 \%(8)$ & \\
\hline Respiratory failure & $62.7 \%(69)$ & $91.2 \%(114)$ & \\
\hline Patient control & $1.8 \%(2)$ & $0.8 \%(1)$ & \\
\hline Hemodynamic instability & $5.5 \%(6)$ & $0.8 \%(1)$ & \\
\hline Severe metabolic acidosis & $3.6 \%(4)$ & $0.8 \%(1)$ & \\
\hline Method of intubation & & & 0.25 \\
\hline $\mathrm{RSI}$ & $73.6 \%(81)$ & $69.6 \%(87)$ & \\
\hline SED & $25.5 \%(28)$ & $30.4 \%(38)$ & \\
\hline OTI & $0.9 \%(1)$ & $0.0 \%(0)$ & \\
\hline Operator PGY level & & & 0.27 \\
\hline 1 & $12.8 \%(14)$ & $7.2 \%(9)$ & \\
\hline 2 & $21.1 \%(23)$ & $16.0 \%(20)$ & \\
\hline 3 & $14.7 \%(16)$ & $12.8 \%(16)$ & \\
\hline 4 & $21.1 \%(23)$ & $29.6 \%(37)$ & \\
\hline 5 & $16.5 \%(18)$ & $24.8 \%(31)$ & \\
\hline 6 & $11.9 \%(13)$ & $8.8 \%(11)$ & \\
\hline Attending & $1.8 \%(2)$ & $0.8 \%(1)$ & \\
\hline
\end{tabular}

${ }^{a}$ Reason for intubation includes airway protection in which the patient is unable to protect the airway from aspiration of secretions; respiratory failure, which includes all etiology of respiratory failure; patient control which is defined as agitation, danger to self, or to facilitate evaluation/procedures; hemodynamic instability, which is defined as shock and severe metabolic acidosis.

NIPPV, noninvasive positive-pressure ventilation; RSI, rapid sequence intubation; SED, sedation-only intubation; OTI, orotracheal intubation without medication; PGY postgraduate year. 
Table 3 Intubation success, complications, and patient outcomes

\begin{tabular}{|c|c|c|c|}
\hline Characteristic & Primary intubation $\%,(n=110)$ & Failed NIPPV \%, $(n=125)$ & $p$ value \\
\hline \multicolumn{4}{|l|}{ Intubation } \\
\hline First attempt success & $77.3 \%(85)$ & $69.6 \%(87)$ & 0.24 \\
\hline Total attempts (mean/median) & $1.25(1)$ & $1.34(1)$ & 0.22 \\
\hline \multicolumn{4}{|l|}{ Outcomes (median (IQR)) } \\
\hline Ventilator days & 5 (3 to 9) & 4 (3 to 10$)$ & 0.52 \\
\hline ICU days & $9(5$ to 15$)$ & $9(5$ to 16$)$ & 0.26 \\
\hline ICU mortality & $35.5 \%(95 \% \mathrm{Cl} 26.4$ to 44.5$)$ & $29.5 \%(95 \% \mathrm{Cl} 21.5$ to 37.7$)$ & 0.40 \\
\hline \multicolumn{4}{|l|}{ Complications } \\
\hline Hypotension & $27.3 \%(30)$ & $32 \%(40)$ & 0.48 \\
\hline Desaturation & $23.6 \%(26)$ & $32 \%(40)$ & 0.19 \\
\hline Aspiration & $1.8 \%(2)$ & $1.6 \%(2)$ & 1.0 \\
\hline$>1$ complication & $10 \%(11)$ & $12.8 \%(16)$ & 0.54 \\
\hline
\end{tabular}

95\% CI 16.1 to 32.7; failed NIPPV 32\%, 95\% CI 23.9 to 40.9). There were no differences in rates of aspiration (primary intubation $1.8 \%$, 95\% CI 0.2 to 6.4 ; failed NIPPV $1.6 \%, 95 \%$ CI 0.2 to 5.7 ) or the number of patients with more than one of the above complications (primary intubation $10 \%, 95 \%$ CI 5.1 to 17.2 ; failed NIPPV $12.8 \%$, 95\% CI 7.5 to 20) (Table 3). There was no difference in the percentage of intubations with a composite complication when patients failed NIPPV in $<6 \mathrm{~h}(54 \%)$ versus $>6 \mathrm{~h}$ (49\%). The unadjusted odds of a composite complication (desaturation, hypotension, or aspiration) was 1.5 (95\% CI 0.90 to 2.51 ). The propensity-adjusted multivariate regression analysis demonstrated that the odds of a composite complication in patients who fail NIPPV was 2.20 (CI 1.14 to 4.25) when corrected for the presence of pneumonia or ARDS and factors known to increase complications of intubation (total attempts and operator experience) (Table 4). The Hosmer-Lemeshow test demonstrates a good fit to the model (0.87). When a composite complication occurred, the unadjusted odds of death in the ICU were 1.79 (95\% CI 1.03 to 3.12 ).

\section{Discussion}

These results demonstrate an increased risk of a composite complication associated with the intubation of critically ill patients who have failed NIPPV compared to patients intubated primarily without a trial of NIPPV. After controlling for potential confounding variables including a diagnosis of pneumonia or ARDS and factors known to increase complications of intubation, such as the number of attempts, operator experience, and the likelihood of being placed on NIPPV, there is an increased odds of a composite complication (hypotension, desaturation, or aspiration) when intubation is delayed due to a trial of NIPPV. When one of these complications occurs, these data show an association with increased unadjusted odds of death in the
ICU. This is the first such association described in the literature and suggests a possible mechanism for the cautions raised by previous authors for the use of NIPPV in mixed respiratory failure $[2,14,15,17,22,23,33]$.

Schnell and colleagues recently reported an increase in NIPPV use over a 15-year period for patients with respiratory failure requiring ventilator support and found that while NIPPV use increased over that time period (42\% by 2011), NIPPV failure was an independent risk factor for mortality [2]. Only patients with acute on chronic respiratory failure showed a 60-day mortality benefit from the use of NIPPV, which has been demonstrated in other studies as well $[7,21]$. Most notably, Schnell et al. found a trend toward increased mortality in immunocompetent patients with respiratory failure, especially in hypoxemic respiratory failure, which has a high rate of intubation and a higher mortality when intubation is delayed by a trial of NIPPV $[2,23]$.

Patients with acute hypoxemic respiratory failure treated with NIPPV require intubation in 30 to $84 \%$ $[2,15,22,23,33]$ and have shown a higher mortality in some studies [15,17]. Gristina et al. found that NIPPV success decreased mortality (36\%) in hematologic malignancy patients with acute lung injury compared to primary intubation (50\%) [20]. However, intubation after failed NIPPV portended a $74 \%$ mortality rate. Although NIPPV has been successful in reducing intubation rates and mortality in patients with COPD exacerbations, NIPPV failure requiring intubation in this patient population has recently been shown to be associated with a $61 \%$ higher odds of mortality than COPD patients intubated primarily [1]. An Agency for Healthcare Research and Quality (AHRQ) report suggests that NIPPV should be used very cautiously, if at all, for respiratory failure not caused by COPD or CHF [14]. The question remains regarding the mechanism mediating the increased risk of 
Table 4 Odds of a composite complication with intubation

\begin{tabular}{|c|c|c|c|c|}
\hline \multirow[b]{3}{*}{ Variable } & \multicolumn{4}{|c|}{ Odds of a composite complication of intubation ${ }^{b}$} \\
\hline & \multicolumn{2}{|c|}{ Unadjusted (crude) } & \multicolumn{2}{|l|}{ Adjusted $^{\mathrm{a}}$} \\
\hline & Odds ratio & $95 \% \mathrm{Cl}$ & Odds ratio & $95 \% \mathrm{Cl}$ \\
\hline Failed NIPPV & 1.50 & 0.90 to 2.51 & 2.20 & 1.14 to 4.25 \\
\hline Pneumonia or ARDS & 2.09 & 1.23 to 3.55 & 1.67 & 0.93 to 2.99 \\
\hline \multicolumn{5}{|l|}{ Total attempts } \\
\hline 1 & Reference & & Reference & \\
\hline 2 & 2.17 & 1.16 to 4.03 & 2.35 & 1.19 to 4.64 \\
\hline 3 & 3.34 & 0.63 to 17.72 & 3.41 & 0.60 to 19.37 \\
\hline \multicolumn{5}{|l|}{ Operator PGY } \\
\hline 1 & Reference & & Reference & \\
\hline 2 & 1.24 & 0.45 to 3.44 & 1.38 & 0.46 to 4.16 \\
\hline 3 & 1.3 & 0.44 to 3.82 & 1.00 & 0.31 to 3.19 \\
\hline 4 & 0.87 & 0.33 to 2.29 & 0.74 & 0.25 to 2.15 \\
\hline 5 & 1.25 & 0.46 to 3.38 & 1.14 & 0.39 to 3.40 \\
\hline 6 & 2.6 & 0.80 to 8.49 & 2.23 & 0.62 to 8.05 \\
\hline Attending & 2.6 & 0.21 to 32.90 & 3.00 & 0.22 to 40.53 \\
\hline Propensity score & - & - & 0.09 & 0.02 to 0.44 \\
\hline
\end{tabular}

${ }^{\mathrm{a}}$ Adjusted for all other variables shown; Hosmer-Lemeshow goodness-of-fit $p$ value $=0.87$; ${ }^{\mathrm{b}}$ the composite complication includes hypotension, desaturation, or aspiration during intubation.

$\mathrm{Cl}$, confidence interval; PGY, postgraduate year, NIPPV, noninvasive positive-pressure ventilation; ARDS, acute respiratory distress syndrome.

death associated with NIPPV failure. Our study suggests that an increase in intubation complications may at least partially explain the increased mortality.

Reintubation for respiratory failure after failed extubation has been associated with higher complications and mortality than patients with a successful extubation [14,34-39]. Additionally, mortality worsens with longer delays in reintubation [34,38,40-42]. While NIPPV can reduce the reintubation rate in this population, failing NIPPV worsens prognosis, significantly delays reintubation and worsens mortality compared to earlier reintubation [18]. Esteban et al. evaluated NIPPV after extubation and found that patients that improved with NIPPV typically improved by $2 \mathrm{~h}$, while patients that required reintubation were intubated at $2 \mathrm{~h}$ and $30 \mathrm{~min}[13,18]$.

Regardless of whether NIPPV is used or not, the intubation of critically ill patients poses an increased risk due to the complex anatomy, physiology, and limited reserve of these patients. Consequently, higher complication rates occur in these patients, including significant hypoxemia in up to $44 \%$ and cardiac arrest in 1 in 50 [28,43-48]. There is significant interest in methods of reducing these risks such as prolonging safe apnea time and preventing desaturation during intubation, including using NIPPV for alveolar recruitment in hypoxemic respiratory failure [49-51]. Positive end-expiratory pressure (PEEP) with the use of NIPPV can be useful for pre-oxygenating patients with shunt physiology prior to intubation [49]; however, our results show that delaying the intubation by using
NIPPV may increase the intubation risk. Although NIPPV may improve pre-oxygenation, Delclaux reported a concerning number of patients with cardiac arrest upon intubation [16].

There are several important limitations to this study. The most important is the retrospective nature of the data collection. We attempted to mitigate this effect by adjusting for the likelihood of being placed on NIPPV and controlling for potential confounding variables that would increase the odds of a complication during intubation. While we attempted to adjust for the likelihood of being placed on NIPPV, only a randomized controlled trial will be able to answer this question definitively. For example, failed NIPPV can occur from poor patient selection with a high severity of illness or worsening of the disease with time while on NIPPV. We attempted to control for poor patient selection by including severity of illness in the propensity score; however, this may not completely account for the bias. The propensity score for receiving NIPPV was generated from variables expected to affect the decision to use NIPPV. There may be variables that might have contributed to the decision to use NIPPV that were not captured, such as the treating physician's impression of the etiology of respiratory failure or the potential for difficulty with intubation not explained by the recorded DACs.

Selection bias may account for a difference in outcomes, particularly if some patients were selected for a trial of NIPPV because of predicted difficulty with intubation at 
the outset. Additionally, we examined all patient deaths in the ICU in the outcome. We feel that this is a more accurate representation of the risk of death, rather than excluding the patients where care was withdrawn given the variability in the decision to withdraw care and its expected dependence on clinical course. By nature of the dataset being patients that were intubated either primarily or after failed NIPPV, patients with a 'do-not-intubate' order related to their goals of care were naturally excluded. Lastly, the patient population these data were selected from were all patients intubated in the ICU, not all patients placed on NIPPV. Therefore, the success rate of NIPPV in our setting is not available. This is likely the explanation for the high percentage of NIPPV failure intubations due to hypoxemic respiratory failure. While these data show the presence of an association, they should be viewed as hypothesis generating and highlight the need for a randomized control trial to definitively examine the relationship between NIPPV failure, intubation complications, and mortality.

\section{Conclusions}

These data show that intubation following failed NIPPV for acute respiratory failure is associated with increased odds of a composite complication (desaturation, hypotension, or aspiration) compared to patients intubated without a trial of NIPPV. Our findings highlight the pressing need for a rigorous investigation into the optimal use of NIPPV. Until data from prospective trials are available, early intubation and mechanical ventilation should be considered in any etiology of acute respiratory failure with a high rate of NIPPV failure, such as pneumonia, ARDS, or extubation failure.

\begin{abstract}
Abbreviations
ACGME: Accreditation Council for Graduate Medical Education; APACHE: acute physiology and chronic health evaluation; ARDS: acute respiratory distress syndrome; CCM: critical care medicine; CHF: congestive heart failure; COPD: chronic obstructive pulmonary disease; CQI: continuous quality improvement; DACs: difficult airway characteristics; GVL: GlideScope video laryngoscopy; ICU: intensive care unit; NIPPV: noninvasive positivepressure ventilation; OTI: orotracheal intubation without medication; PGY: postgraduate year; Pulm/CCM: pulmonary and critical care medicine; RSI: rapid sequence intubation; SAPS: simplified acute physiology score; SED: sedation-only intubation.
\end{abstract}

\section{Competing interests}

The authors declare that they have no competing interests.

\section{Authors' contributions}

JMM, JB, LS, SW, and JCS conceived the study. JMM designed the data collection instrument and managed the database. JMM, CH, and JB performed statistical analysis in the study. JMM, JCS, CH, SW, LS, DH, KH, and JB contributed to the drafting of the manuscript. JMM takes responsibility for the paper as a whole. All authors read and approved the final manuscript.

\section{Acknowledgements}

The authors would like to thank Uwe Stolz, PhD for statistical assistance. We would also like to thank Michael Molloy, BS, and Matthew Douglas, MD for assistance with data extraction and chart review.
This work was presented at the SCCM 2014 annual congress in San Francisco, CA.

\section{Author details}

${ }^{1}$ Section of Pulmonary, Critical Care, Allergy and Sleep, Department of Medicine, University of Arizona, 1501 N Campbell Ave., Tucson, AZ 85721, USA. ${ }^{2}$ Department of Emergency Medicine, University of Arizona, 1609 N. Warren Ave., Tucson, AZ 85724, USA. ${ }^{3}$ Division of Emergency Critical Care, Department of Emergency Medicine, University of Michigan Health System, 1500 E Medical Center Drive, Ann Arbor, Ml 48109, USA. ${ }^{4}$ University of Arizona, 1609N Warren, FOB 122C, Tucson, AZ 85719, USA.

Received: 14 November 2014 Accepted: 17 February 2015

Published online: 06 March 2015

\section{References}

1. Chandra D, Stamm JA, Taylor B, Ramos RM, Satterwhite L, Krishnan JA, et al. Outcomes of noninvasive ventilation for acute exacerbations of chronic obstructive pulmonary disease in the United States, 1998-2008. Am J Respir Crit Care Med. 2012;185:152-9.

2. Schnell D, Timsit JF, Darmon M, Vesin A, Goldgran-Toledano D, Dumenil AS, et al. Noninvasive mechanical ventilation in acute respiratory failure: trends in use and outcomes. Intensive Care Med. 2014;40:582-91.

3. Liesching $T$, Kwok H, Hill NS. Acute applications of noninvasive positive pressure ventilation. Chest. 2003;124:699-713.

4. Bott J, Carroll MP, Conway JH, Keilty SE, Ward EM, Brown AM, et al. Randomised controlled trial of nasal ventilation in acute ventilatory failure due to chronic obstructive airways disease. Lancet. 1993;341:1555-7.

5. Brochard L, Mancebo J, Wysocki M, Lofaso F, Conti G, Rauss A, et al. Noninvasive ventilation for acute exacerbations of chronic obstructive pulmonary disease. N Engl J Med. 1995;333:817-22.

6. Girou E, Brun-Buisson C, Taille S, Lemaire F, Brochard L. Secular trends in nosocomial infections and mortality associated with noninvasive ventilation in patients with exacerbation of COPD and pulmonary edema. JAMA. 2003;290:2985-91.

7. Kramer N, Meyer TJ, Meharg J, Cece RD, Hill NS. Randomized, prospective trial of noninvasive positive pressure ventilation in acute respiratory failure. Am J Respir Crit Care Med. 1995;151:1799-806.

8. Lightowler JV, Wedzicha JA, Elliott MW, Ram FS. Non-invasive positive pressure ventilation to treat respiratory failure resulting from exacerbations of chronic obstructive pulmonary disease: cochrane systematic review and meta-analysis. BMJ. 2003;326:185.

9. Masip J, Betbese AJ, Paez J, Vecilla F, Canizares R, Padro J, et al. Non-invasive pressure support ventilation versus conventional oxygen therapy in acute cardiogenic pulmonary oedema: a randomised trial. Lancet. 2000;356:2126-32.

10. Nava S, Carbone G, DiBattista N, Bellone A, Baiardi P, Cosentini R, et al. Noninvasive ventilation in cardiogenic pulmonary edema: a multicenter randomized trial. Am J Respir Crit Care Med. 2003;168:1432-7.

11. Plant PK, Owen JL, Elliott MW. Early use of non-invasive ventilation for acute exacerbations of chronic obstructive pulmonary disease on general respiratory wards: a multicentre randomised controlled trial. Lancet. 2000;355:1931-5.

12. Hilbert $G$, Gruson D, Vargas F, Valentino R, Gbikpi-Benissan G, Dupon M, et al. Noninvasive ventilation in immunosuppressed patients with pulmonary infiltrates, fever, and acute respiratory failure. N Engl I Med. 2001;344:481-7.

13. Truwit JD, Bernard GR. Noninvasive ventilation-don't push too hard. N Engl J Med. 2004;350:2512-5.

14. Williams JW, Cox CE, Hargett CW, Gilstrap DL, Castillo CE, Govert JA, et al. In: Noninvasive positive-pressure ventilation (NPPV) for acute respiratory failure. Rockville (MD); 2012. AHRQ comparative effectiveness reviews]. http://www.ncbi.nlm.nih.gov/pubmed/22876372

15. Carrillo A, Gonzalez-Diaz G, Ferrer M, Martinez-Quintana ME, Lopez-Martinez A, Llamas N, et al. Non-invasive ventilation in community-acquired pneumonia and severe acute respiratory failure. Intensive Care Med. 2012;38:458-66.

16. Delclaux C, L'Her E, Alberti C, Mancebo J, Abroug F, Conti G, et al. Treatment of acute hypoxemic nonhypercapnic respiratory insufficiency with continuous positive airway pressure delivered by a face mask: a randomized controlled trial. JAMA. 2000;284:2352-60. 
17. Demoule A, Girou E, Richard JC, Taille S, Brochard L. Benefits and risks of success or failure of noninvasive ventilation. Intensive Care Med. 2006;32:1756-65.

18. Esteban A, Frutos-Vivar F, Ferguson ND, Arabi Y, Apezteguia C, Gonzalez M, et al. Noninvasive positive-pressure ventilation for respiratory failure after extubation. N Engl J Med. 2004;350:2452-60.

19. Ferrer M, Esquinas A, Leon M, Gonzalez G, Alarcon A, Torres A. Noninvasive ventilation in severe hypoxemic respiratory failure: a randomized clinical trial. Am J Respir Crit Care Med. 2003;168:1438-44.

20. Gristina GR, Antonelli M, Conti G, Ciarlone A, Rogante S, Rossi C, et al. Noninvasive versus invasive ventilation for acute respiratory failure in patients with hematologic malignancies: a 5-year multicenter observational survey. Crit Care Med. 2011;39:2232-9.

21. Keenan SP, Kernerman PD, Cook DJ, Martin CM, McCormack D, Sibbald WJ. Effect of noninvasive positive pressure ventilation on mortality in patients admitted with acute respiratory failure: a meta-analysis. Crit Care Med. 1997;25:1685-92

22. Thille AW, Contou D, Fragnoli C, Cordoba-lzquierdo A, Boissier F, BrunBuisson C. Non-invasive ventilation for acute hypoxemic respiratory failure: intubation rate and risk factors. Crit Care. 2013;17:R269.

23. Thille AW, Frat JP, Brun-Buisson C. Trends in use and benefits of noninvasive ventilation as first-line therapy in acute respiratory failure. Intensive Care Med. 2014;40:1179-80

24. Schwartz DE, Matthay MA, Cohen NH. Death and other complications of emergency airway management in critically ill adults. A prospective investigation of 297 tracheal intubations. Anesthesiology. 1995;82:367-76.

25. Reynolds SF, Heffner J. Airway management of the critically ill patient: rapidsequence intubation. Chest. 2005;127:1397-412.

26. Mort TC. Complications of emergency tracheal intubation: hemodynamic alterations-part I. J Intensive Care Med. 2007;22:157-65.

27. Mort TC. Complications of emergency tracheal intubation: immediate airway-related consequences: part II. J Intensive Care Med. 2007;22:208-15.

28. Jaber S, Amraoui J, Lefrant JY, Arich C, Cohendy R, Landreau L, et al. Clinical practice and risk factors for immediate complications of endotracheal intubation in the intensive care unit: a prospective, multiple-center study. Crit Care Med. 2006;34:2355-61.

29. Gudzenko V, Bittner EA, Schmidt UH. Emergency airway management. Respir Care. 2010;55:1026-35.

30. Benedetto WJ, Hess DR, Gettings E, Bigatello LM, Toon H, Hurford WE, et al. Urgent tracheal intubation in general hospital units: an observational study. J Clin Anesth. 2007;19:20-4.

31. Mosier J, Douglas M, Molloy M, Bloom J, Snyder L, Sakles J. Odds of adverse events of intubation following failed non-invasive positive pressure ventilation. Crit Care Med. 2013:41(12):A90

32. Austin PC. An introduction to propensity score methods for reducing the effects of confounding in observational studies. Multivar Behav Res. 2011;46:399-424

33. Antonelli M, Conti G, Esquinas A, Montini L, Maggiore SM, Bello G, et al. A multiple-center survey on the use in clinical practice of noninvasive ventilation as a first-line intervention for acute respiratory distress syndrome. Crit Care Med. 2007;35:18-25.

34. Epstein SK, Durbin Jr CG. Should a patient be extubated and placed on noninvasive ventilation after failing a spontaneous breathing trial? Respir Care. 2010;55:198-206. discussion 207-198.

35. El Solh AA, Bhat A, Gunen H, Berbary E. Extubation failure in the elderly. Respir Med. 2004;98:661-8.

36. Epstein SK, Ciubotaru RL, Wong JB. Effect of failed extubation on the outcome of mechanical ventilation. Chest. 1997;112:186-92.

37. Esteban A, Alia I, Gordo F, Fernandez R, Solsona JF, Vallverdu I, et al. Extubation outcome after spontaneous breathing trials with T-tube or pressure support ventilation. The Spanish Lung Failure Collaborative Group. Am J Respir Crit Care Med. 1997;156:459-65.

38. Esteban A, Alia I, Tobin MJ, Gil A, Gordo F, Vallverdu I, et al. Effect of spontaneous breathing trial duration on outcome of attempts to discontinue mechanical ventilation. Spanish lung failure collaborative group. Am J Respir Crit Care Med. 1999;159:512-8.

39. Gowardman JR, Huntington D, Whiting J. The effect of extubation failure on outcome in a multidisciplinary Australian intensive care unit. Crit Care Resusc. 2006;8:328-33.
40. Demling $\mathrm{RH}$, Read T, Lind LJ, Flanagan HL. Incidence and morbidity of extubation failure in surgical intensive care patients. Crit Care Med. 1988; 16:573-7.

41. Epstein SK, Ciubotaru RL. Independent effects of etiology of failure and time to reintubation on outcome for patients failing extubation. Am J Respir Crit Care Med. 1998;158:489-93.

42. Tahvanainen J, Salmenpera M, Nikki P. Extubation criteria after weaning from intermittent mandatory ventilation and continuous positive airway pressure. Crit Care Med. 1983;11:702-7.

43. Cook TM, Woodall N, Harper J, Benger J. Major complications of airway management in the UK: results of the Fourth National Audit Project of the Royal College of Anaesthetists and the Difficult Airway Society. Part 2: intensive care and emergency departments. Br J Anaesth. 2011;106:632-42.

44. Griesdale DE, Bosma TL, Kurth T, Isac G, Chittock DR. Complications of endotracheal intubation in the critically ill. Intensive Care Med. 2008;34:1835-42

45. Mort TC. The incidence and risk factors for cardiac arrest during emergency tracheal intubation: a justification for incorporating the ASA Guidelines in the remote location. J Clin Anesth. 2004;16:508-16.

46. Simpson GD, Ross MJ, McKeown DW, Ray DC. Tracheal intubation in the critically ill: a multi-centre national study of practice and complications. $\mathrm{Br} J$ Anaesth. 2012;108:792-9.

47. Walz JM, Zayaruzny M, Heard SO. Airway management in critical illness. Chest. 2007;131:608-20.

48. Le Tacon S, Wolter P, Rusterholtz T, Harlay M, Gayol S, Sauder P, et al. Complications of difficult tracheal intubations in a critical care unit. Ann Fr Anesth Reanim. 2000;19:719-24.

49. Baillard C, Fosse JP, Sebbane M, Chanques G, Vincent F, Courouble $P$, et al. Noninvasive ventilation improves preoxygenation before intubation of hypoxic patients. Am J Respir Crit Care Med. 2006;174:171-7.

50. Weingart SD, Levitan RM. Preoxygenation and prevention of desaturation during emergency airway management. Ann Emerg Med. 2012;59:165-75.

51. Tang L, Li S, Huang S, Ma H, Wang Z. Desaturation following rapid sequence induction using succinylcholine vs. rocuronium in overweight patients. Acta Anaesthesiol Scand. 2011;55:203-8.

\section{Submit your manuscript to a SpringerOpen ${ }^{\odot}$ journal and benefit from:}

- Convenient online submission

Rigorous peer review

- Immediate publication on acceptance

- Open access: articles freely available online

- High visibility within the field

- Retaining the copyright to your article

Submit your next manuscript at $>$ springeropen.com 